\title{
Public Childcare Provision and Employment Participation of East and West German Mothers with different Educational
} Backgrounds

\author{
Gundula Zoch ${ }^{\text {a }}$
}

[Published as Zoch, Gundula (2020): Public childcare provision and employment participation of East and West German mothers with different educational backgrounds. In: Journal of European Social Policy (Advance online publication). DOI: 10.1177/0958928719892843.]

\begin{abstract}
By focusing on a period of a major public childcare expansion in Germany, this study investigates whether higher levels of childcare coverage for under-threes have been positively associated with employment among mothers with different educational backgrounds. Both standard economic labour theories and sociological theories presume that the effect of public childcare provision varies with mothers' educational attainment. The analysis links countylevel data on annual childcare ratios with individual-level data from the Socio-Economic Panel Study (2007-2016). To match mothers with similar characteristics in counties with childcare ratios above and below the annual median within East and West Germany, entropy balancing is applied. Findings indicate a positive relationship between childcare provision and maternal employment, with more pronounced associations for mothers with at least a vocational degree, those with a second birth, and those who receive full-time access to childcare.
\end{abstract}

Keywords: childcare; educational inequality; family policy; maternal employment; balancing; socioeconomic background

Funding: This work was supported by a grant from the Bamberg Graduate School of Social Sciences (funded by the German Research Foundation - DFG (GSC1024)).

Acknowledgements: The author is grateful for comments on an earlier version of this paper from participants at the ECSR Conference 2017 and the Annual ESPAnet Conference 2017 as well as for helpful suggestions from Nadja Wehl, Stefanie Heyne and Tina Baier and those at invited seminars at University of Bamberg and a joint workshop from the Universities Trento, Bamberg, Tilburg and Milan at University of Trento.

${ }^{a}$ Dr. Gundula Zoch, Leibniz Institute for Educational Trajectories, Wilhelmsplatz 3, 96047 Bamberg, Germany gundula.zoch@lifbi.de 


\section{Public Childcare Provision and Employment Participation of East and West German Mothers with different Educational Backgrounds}

\section{Introduction}

In most European Member States, women continue to leave their jobs, or at least significantly reduce their working hours after childbirth, so increasing childcare provision remains a key instrument in promoting maternal employment. To increase maternal employment, in 2002 the European Council set precise coverage target rates for the provision of childcare. By 2010, all Member States should have been providing formal childcare to at least 33 percent of underthree-year-olds (European Commission, 2018).

In most European countries, however, this target has not yet been achieved (European Commission, 2018), while the use of available capacities is socially selective. Across Europe, it is mainly high-skilled or high-income parents who tend to make use of formal childcare (e.g., van Lancker and Ghysels, 2016). ${ }^{1}$ In social policy research this is referred to as the Matthew effect (e.g., Pavolini and van Lancker, 2018), according to which policy reforms, such as the expansion of childcare, aim to reduce social inequalities, but actually favour better-off families more than disadvantaged families. If the latter use childcare services less, the potential gains from high-quality childcare, such as increased maternal employment, and thus family income, and returns to education will predominantly benefit already-favoured families. This reinforces existing social inequalities.

Although it is generally assumed that increased public childcare provision fosters the employment of mothers regardless of their educational background, there are mechanisms that favour a Matthew effect in childcare use. Inequalities are likely to persist if less-educated parents have limited access to formal childcare, or continue to prefer informal care(Pavolini and van Lancker, 2018; Stahl et al., 2018; van Lancker and Ghysels, 2016). If public childcare provision is insufficient, childcare providers are likely to implement access criteria, such as priority access for working parents (Stahl et al., 2018). As more highly educated mothers are more likely to work, and often work more hours, they are likely to be the main beneficiaries of such access rules. This leads to inequality and thus to a socially stratified use of childcare. Similarly, parental fees could prevent particularly disadvantaged groups, such as low-skilled parents with lower household incomes, from using childcare services. In addition to restricted access due to limited availability or affordability, less educated parents could also opt for parental childcare due to persistently more conservative work-care preferences (Steiber and 
Haas, 2012; Zoch and Schober, 2018), thus creating socially unequal childcare use from the demand side.

Given the considerable number of European Member States that have significantly increased their childcare capacities, and the still very selective use of childcare services across Europe, the question remains as to whether higher levels of public childcare provision promote the employment of all mothers, regardless of their educational background. By focusing on a major public childcare expansion in Germany, this study examines whether higher levels of childcare provision for under-threes are positively associated with the employment of mothers with different educational backgrounds.

The comprehensive childcare reform in Germany, together with current data availability, provides a good opportunity to examine the link between different levels of public childcare and educational differences in maternal employment for various reasons. Germany is wellknown for its considerably low maternal employment rate, long childbirth-related employment interruptions and high part-time rates, particularly in West Germany (Rosenfeld et al., 2004). For this reason, and in line with EU policy-making, Germany has implemented a major childcare expansion for under-threes. Thus, Germany is one of the European countries with a comparatively strong increase in childcare capacities (European Commission, 2018). However, the increase in childcare coverage varies widely across the country. Compared to previous cross-sectional and longitudinal studies, which have focused on pre-expansion periods without large exogenous variation in childcare provision (e.g. Kreyenfeld and Hank, 2000; Schober and Spieß, 2015), this temporal and regional variation is well suited to better examine whether educational differences in maternal employment are related to lower levels of public childcare provision. Second, Germany provides the unique opportunity to investigate the consequences of higher childcare coverage levels separately in East and West Germany. The two regions continue to differ remarkably in their initial level of childcare, maternal employment rates, labour market opportunities and work-care norms regarding non-parental childcare and maternal employment. By taking into account these long-standing and persistent East-West differences, the study expands upon previous research which has concentrated predominantly on single country studies without large variation in the labour market and cultural context.

To examine the relationship between higher levels of public childcare and educational differences in maternal employment, the study links rich individual and household panel information from the German Socio-Economic Panel (2007-2016) with county-level (Kreisebene) data on childcare availability. Thus, it exploits the temporal and regional variation in the expansion of childcare services across counties within and between East and West 
Germany. With rich individual and household information, the study is one of the first to examine educational disparities in marginal, part-time and full-time employment, where previous studies focused only on general maternal participation in employment. At the same time, it also examines whether maternal employment is more pronounced for higher coverage levels providing full-time places only, or both full- and part-time places. ${ }^{2}$ Finally, in view of some recent findings on more pronounced employment effects after a second birth (Zoch and Hondralis, 2017), it empirically investigates whether the relationship between childcare and maternal employment is stronger after first or second births.

\section{Public Childcare and Maternal Employment in East and West Germany}

This section briefly describes the developments in maternal employment and childcare policies for under-threes, focusing on institutional characteristics that favour educational inequalities in maternal employment.

Persistent East-West differences in maternal employment have frequently been explained as a consequence of different family policies before the German reunification. In West Germany, the lack of public and private childcare facilities for under-threes and long parental leave periods have long reinforced the model of the (modified) male breadwinner (Rosenfeld et al., 2004). Conversely, in the FRG, comparatively short parental leave entitlements and extensive levels of public childcare starting at a very young age have encouraged East German mothers to return to work faster and more often to full-time employment (Rosenfeld et al., 2004). Hence there, equal labour market participation of women from different educational backgrounds was the norm and represents a central element of East German women's identity even today.

Since 1990, employment trends in East and West Germany converged, and part-time employment has become the prevalent arrangement (e.g., Konietzka and Kreyenfeld, 2010). Nevertheless, higher childcare coverage levels in East Germany, predominantly provided fulltime, have continued to enable shorter interruption durations and returns to long part-time or full-time employment (Rosenfeld et al., 2004). In addition, long parental leave entitlements and worsening labour market opportunities for low-skilled workers seemed to increase educational disparities in maternal employment until the mid-2000s, particularly in West Germany. Consequently, it is predominantly highly educated mothers who work full-time (Konietzka and Kreyenfeld, 2010).

To meet the European childcare policy targets, Germany started to increase public childcare provision for under-threes in 2005. This was accompanied by the introduction of a legal childcare entitlement of about four to five hours a day for children aged one or older from 
August 2013. Although the federal government financially supports the reform, it is planned and implemented by the federal states and administrative counties. There are therefore considerable differences in the expansion of services, facilities' opening hours, access to facilities, parental fees and the quality of childcare (Spieß et al., 2008).

Childcare expansion has increased attendance rates tremendously, albeit starting from different levels in East and West Germany. In 2006 almost all East German counties provided childcare to more than 30 percent of all under-threes, whereas West German counties seldom reached more than 20 percent (Federal Statistical Office, 2018). Between 2006 and 2016, coverage rates increased from 8 to 28 percent in West Germany and from 40 to 52 percent in East Germany (Federal Statistical Office, 2018) (see Figures A5 and A6 in the Online Appendix). However, these averages mask large regional differences in the increase in childcare services. In 2016, average provision ranged from 45 to 63 percent in East Germany and from 14 to 48 percent in West Germany (Federal Statistical Office, 2018). Additionally, full-time coverage continues to vary widely: in 2016 more than 40 percent of East German under-threes attended childcare more than 7 hours a day, compared to only 13 percent in West Germany (Federal Statistical Office, 2018). This study will exploit the temporal and regional differences in the expansion of childcare services across counties within and between East and West Germany.

Although childcare capacities increased tremendously, childcare take-up remains socially stratified. However, childcare costs seem to be less relevant for explaining socially stratified childcare use and maternal employment than the actual availability of childcare places. Childcare coverage costs are mostly publicly financed, and hence parental fees (on average about 14 percent) are often income-dependent and well below the OECD average (Schober and Spieß, 2015). Although parents' childcare expenditures have increased over time, particularly for high-income households, the increase has not been significant for low-income or at-risk-ofpoverty families, as a considerable number of these parents pay no fees at all (Schmitz et al., 2017).

As an explanation for socially stratified childcare use in Germany, formal and informal childcare access criteria appear to be more important. Until the legal entitlement was introduced in 2013, children whose parents were in employment or education were given priority access. Recent research shows that it has become common practice to give priority access to children of dual-earner or single parents and those with an older sibling in the same institution when applications exceed available places (Stahl et al., 2018). It can therefore be assumed that highly educated mothers in particular, who are more likely to be gainfully employed and live in two- 
earner households, will benefit from these access rules and therefore make more use of the expanded childcare capacities.

Taken together, the still insufficient childcare capacities, the long-standing historical, cultural and labour market differences across Germany, and the differences in formal and informal access criteria to a childcare place suggest that the relationship between childcare provision and maternal employment most likely varies with mothers' educational attainment.

\section{Previous Research}

By exploiting regional and temporal variation in childcare provision, most international studies have highlighted the overall positive employment effects of public childcare (see Morrissey, 2017 for an overview). The results vary, however, depending on the context, with larger effects on maternal employment discernible where childcare was previously severely rationed (Brilli et al., 2016 on Italy), but sometimes only small or insignificant effects due to substitution or heterogeneous reform effects (e.g., Havnes and Mogstad, 2011). Additionally, international studies either focus on childcare costs or analyse childcare coverage effects primarily in contexts dominated by for-profit providers. Their findings may therefore not be applicable to the German context, with its comparatively moderate childcare costs, (almost) total lack of forprofit providers (Del Boca and Vuri, 2007) and the comparatively low employment orientation of mothers with small children in the past.

For Germany, some studies focusing on the impact of childcare in the pre-reform period show no significant correlation between childcare and maternal employment, especially for West Germany (e.g., Kreyenfeld and Hank, 2000). However, these studies use childcare data provided only once every four years and covering a period with very low levels of, and only low exogenous variation in childcare provision. Overall, these pre-reform studies do not sufficiently reflect the current opportunity structures of mothers enabled by the strong expansion of childcare places.

Considering the period after the start of the childcare expansion, to date, evidence on employment effects of public childcare is limited. Micro-simulations predicted an increase in maternal employment, with particularly pronounced effects among low- or medium-income families (Haan and Wrohlich, 2011; Bonin et al., 2013). Conversely, using cross-sectional survey data for 2010 and 2011, Schober and Spieß (2015) found no positive employment effects once they controlled for childcare quality, particularly for East Germany. With regard to the expansion period between 2006 and 2014, higher childcare coverage levels were only modestly associated with shorter employment interruption durations, and only among West German 
mothers with a second birth (Zoch and Hondralis, 2017). Due to low observation figures, the authors were unable to investigate any educational disparities. Recent trends point to increasing educational disparities in childcare use, with mothers with at least a vocational qualification mainly using formal childcare, and exclusive parental care increasing mainly for low-skilled mothers (Stahl and Schober, 2018). However, the study did not account for labour market opportunities and childcare provision. It is therefore not yet clear whether higher levels of public childcare provision are positively linked to the employment of mothers with different educational backgrounds in East and West Germany.

\section{Theoretical Framework}

To explain educational disparities in maternal employment the theoretical framework draws on three major factors: firstly, different opportunity costs due to educational group-specific income and career perspectives; second, different gender ideologies towards maternal employment or non-parental care; and third, differences in the actual and perceived opportunity structure of childcare provision.

According to the rational choice perspective in economic theories, it is highly-educated mothers that increase their labour supply the most when childcare becomes widely available (Becker, 2009; Mincer and Polachek, 1974). Human capital theory holds that highly-educated individuals are generally more likely to work than low-skilled because of higher opportunity costs in terms of foregone income and potential career opportunities (Mincer and Polachek, 1974). Access to affordable childcare enables mothers to return to work and therefore an increase in public childcare increases maternal employment. Nevertheless, although publicly subsidised childcare in Germany has increased in recent years, there are still not enough places and parental fees are not always low. Highly educated mothers with higher opportunity costs of non-employment are therefore presumed to make greater use of the available supply compared to low-skilled mothers.

However, narrow rational choice and cost-benefit explanations may not be sufficient to fully explain educational disparities in maternal employment. Particularly from an international perspective, the income-dependent parental fees in Germany are likely to appear comparatively moderate. Thus, childcare and opportunity costs do not necessarily seem to be the only decision factors, so that educational differences in maternal employment may not be fully explained by a pure cost-benefit decision alone.

As a first alternative to narrow rational cost-benefit theories, identity constructivist approaches (Stets and Burke, 2000) can be applied to explain educational disparities in 
childcare take-up and maternal employment with differences in attitudes and ideologies. In line with theoretical assumptions on role exposure in constructivist approaches and role theory (Stets and Burke, 2000), previous research shows that less traditional gender ideologies towards maternal employment and non-parental care are significantly correlated with mothers' employment (Steiber and Haas, 2012). With more public childcare provision, individual preferences for the type of childcare and for one's own working life can be implemented more easily. Since previous research has shown that highly educated mothers are particularly likely to state more progressive attitudes towards non-parental care and maternal employment (Steiber and Haas, 2012), it is assumed that these mothers will increase their employment the most if childcare becomes widely available.

Additionally, the accommodation model on childcare choice presumes educational inequalities in work-care arrangements not only to result from education-specific attitudes, but also from differences in parents' actual and perceived opportunity structures (Chaudry et al., 2010; Meyers and Jordan, 2006). Although childcare provision has increased across Germany, regional disparities remain persistent, particularly for full-time childcare places. With insufficient places, childcare providers are likely to implement access criteria that lead to inequality, and thus to socially stratified use of childcare. Studies show for Germany that the priority access for children of dual-earner parents seems to have become common practice (Stahl et al., 2018). It is therefore assumed that highly skilled mothers are favoured by these access rules. As a result, they will primarily benefit from the expanded care capacities, which is expected to increase educational disparities in maternal employment.

But even when facing a comparable infrastructure, parents may evaluate their local childcare opportunity structure differently due to imperfect and socially stratified information (Chaudry et al., 2010; Meyers and Jordan, 2006). Educational disparities in work-care arrangements may thus be traced back to a lack of parents' awareness about childcare availability or entitlement, or inadequate understanding about the application procedure or issues such as priority enrolment criteria or waiting lists, as well as parents' misperceptions about the benefits of early education (Stahl et al., 2018). It can be assumed that less educated parents have greater information asymmetries and therefore use childcare less, meaning they are less likely to be gainfully employed.

In summary, both economic and sociological theories presume that the higher the level of childcare coverage for under-threes, particularly if full-time, the more likely it is that mothers will work (H1). Moreover, the different theoretical frameworks suggest that the relationship 
between childcare and maternal employment is more pronounced among highly skilled mothers compared to low-skilled mothers $(H 2)$.

Given persistently higher childcare coverage levels and less traditional work-care norms due to the socialist legacy of maternal full-time employment in East Germany, the positive relationship between childcare and maternal employment is presumed to be more pronounced in East Germany. Conversely, in West Germany, public childcare continues to be scarce, particularly full-time care and, thus, together with persistently more traditional work-care norms, higher levels of childcare coverage are likely to be linked to part-time rather than fulltime employment. Given the long tradition of maternal employment and non-parental care among all educational groups of mothers as well as persistently higher childcare levels today, socially stratified preferences and information on childcare availability might be less important for childcare take-up and maternal employment in East Germany. Where there are limited capacities such as in West Germany, it is particularly dual-earner families, and thus more educated parents, who benefit most from priority access regulations. Thus, taken together, educational disparities in the relationship between higher levels of childcare coverage and maternal employment are presumed to be more distinct in West Germany compared to East Germany $(H 3)$.

\section{Data and Estimation Strategy}

The analysis combines annual administrative records on county-level (Kreisebene) childcare coverage from the Federal Statistical Office with individual-level data from the German SocioEconomic Panel (SOEP) between 2007 and 2016 (Wagner et al., 2007). The sample includes mothers aged 18 to 47 with a first or second child under three. Mothers who move between counties during the observation period, and mothers without any work experience are excluded. In total, 2,367 mothers in 354 of the 402 counties in Germany are observed, 72 of which are located in East Germany. The final sample consists of 4,362 observations of 1,817 West German mothers, including 992 first and 1168 second births (1,905 first and 2,457 second birth observations). For East Germany, 1,321 observations of 550 mothers, including 290 first and 359 second children (575 first and 746 second birth observations) are observed. 231 West German and 58 East German mothers are observed with a first and second birth. 


\section{Estimation Strategy}

To investigate whether higher levels of public childcare provision support the employment of all mothers independently of their educational background, the analysis seeks to compare the employment behaviour of mothers in counties offering higher or lower levels of childcare. Previous research demonstrates that childcare take-up is not random, but correlated with individual and household characteristics (e.g., Stahl and Schober, 2018). Additionally, there remains a risk that mothers from counties with varying childcare provision differ significantly in their individual and household characteristics, as differences in the increase of childcare services across Germany are associated with county characteristics such as employment rates and productivity (Andronescu and Carnes, 2015). Although conventional regression models perform even if treatment and control groups differ in their covariate distribution, effect estimates are likely to be biased, particularly when the estimation relies heavily on extrapolation (Stuart, 2010).

To compare the employment behaviour of mothers with access to higher levels of childcare coverage with mothers with comparable individual and regional characteristics but lower childcare coverage levels, a control was applied, designed using a matching technique. ${ }^{3}$ The study used annual county-level childcare attendance ratios to distinguish a treatment group of mothers from counties with childcare ratios above the annual median from a control group of mothers with below-median childcare ratios. To make both groups comparable, i.e. to balance the covariate distribution, the non-parametric matching technique of entropy balancing (EB) (Hainmueller, 2012) was applied. Thus, mothers in the control group with lower childcare coverage levels, who were more similar to mothers in the treatment group, received higher weights. While conventional matching techniques achieve a balanced covariate distribution only indirectly, and thus often fail to achieve an exact matching of all pre-specified moments and for all covariates (Caliendo and Kopeinig, 2008), EB calculates weights directly. As cases of statistically similar pairs of mothers cannot be matched or discarded, but receive weights that vary smoothly, EB makes use of all available cases. In sum, EB reweights the observations of the control group so that the variation in the treatment, that is, whether mothers have access to above-median childcare, is only related to the availability of childcare provision, and not correlated with mothers' individual and regional background characteristics (Gambaro et al. 2019).

The empirical strategy was implemented in two steps. The weights for the control group of mothers with below-median childcare coverage were first determined by applying the userwritten Stata command ebalance (Hainmueller, 2012). The calculated weights were then 
included in the multinomial logistic regressions models calculated in the second step. In these models, a categorical variable on maternal employment, distinguishing between unemployment, marginal employment of fewer than 15 hours a week, and full- and part-time employment, was regressed on a dummy variable, indicating an above-median annual childcare ratio. To adjust the standard error of the estimated effect and to reduce the unexplained variance in maternal employment, all conditioning variables added in the first step were included in the regression models (Gambaro et al. 2019; Hainmueller, 2012).

For East and West Germany, all multinomial logistic regression models were estimated separately for mothers with university or college degrees, vocational training, or lower qualifications. Unfortunately, too few observations meant that separate models for low-skilled East German mothers were not possible. However, joint models with medium-skilled mothers showed no statistically significant effects. In the second step, it was examined whether the associations between childcare and employment were more pronounced when family formation is more likely to be completed. Mothers were therefore additionally distinguished according to their first and second birth. Unfortunately, the sample contained too few low-skilled West German mothers to distinguish between first and second births. Lastly, logistic regressions were estimated to investigate whether the association between childcare and full-time employment was stronger for the availability of full-time childcare services compared to the general coverage rate, which included both full- and part-time places.

\section{Maternal Employment and Childcare Availability}

Annually all SOEP respondents provide information on their employment status, leave take-up, and average actual weekly working hours. Many mothers with small children and longer breaks from work without employment, especially in West Germany, often identify themselves not as unemployed but as homemakers or choose multiple answer categories. It is therefore not always possible to distinguish clearly between unemployed and employed mothers on parental leave and to examine them in separate categories. As a dependent variable, the analyses used a categorical variable indicating whether the mother is not working (including unemployment, leave take-up, and homemakers), working in marginal (less than 15 hours a week), part-time (15 to 35 weekly hours) or full-time employment (35 weekly hours or more).

The key independent variable distinguished for each year between mothers in counties with a childcare ratio above and below the annual median. Due to the very different distribution, an east-west specific median was used for mothers in East and West Germany. The childcare ratio was defined as the annual share of under-threes enrolled in any form of subsidised childcare 
services, including half-day or full-day childcare centres or child-minders. ${ }^{4}$ Conversely, fulltime childcare coverage rates included only childcare places available for more than 7 hours a day (see Figure A5 and A6 in the Appendix). To address concerns about reverse causality between greater childcare coverage and maternal employment participation, lagged variables of the childcare measures were used.

Table A1 in the Online appendix shows summary statistics on all outcomes for East and West German mothers by mothers' education levels and first or second birth in counties with childcare ratios above or below the annual median.

\section{Conditioning variables}

A large number of conditioning variables were included in both the matching and the regression equations (Gambaro et al. 2019). On the individual level, models accounted for mothers' ages and migration backgrounds as well as mothers' pre-birth employment statuses (full-time, parttime, not employed and missing information), pre-birth inflation-adjusted incomes (in 2011 Euros), cumulated full-time and part-time work experience in years, and the perceived importance of career success to further control for mothers' work orientation before childbirth. On the household level, models included: number of children, youngest child's age $(<1,1-2$, $2+$ years), if the child was born after the parental leave reform of 2007, and current equivalised $\log$ net household income (in 2011 Euros). To account for county-level variation in labour markets and productivity, which is most likely to affect the expansion in childcare services and maternal employment simultaneously, all models include the following county-level controls, provided annually by the Federal Statistical Office: unemployment rate, GDP per capita, a dummy indicating rural counties and the number of public servants per 1000 inhabitants. Similar to the childcare measure, lagged variables of the county-level controls were used. To account for further unobserved influences, all models included period dummies.

Table A2 presents summary statistics of selected conditioning variables for mothers with a county-level childcare ratio above or below the annual median in East and West Germany. In West Germany, mothers with access to above-median childcare provision were, for example, significantly more likely to have a college degree, a higher household income, and to live in urban areas with more favourable economic and labour market characteristics. In contrast, East German mothers with above-median childcare provision were significantly more likely to live in rural counties, have a somewhat higher employment rate, and lower GDP per capita. Overall, the estimated standardised bias seems less pronounced for most variables at individual and household level than for variables at regional level, especially in East Germany. After the 
reweighting based on entropy balancing, for each conditioning variable the mean was identical in the two groups of mothers in East and West Germany, and the estimated standardised bias was below the recommended level of 5 percent (Caliendo and Kopeinig, 2008).

\section{Results}

Results are displayed graphically by plotting point estimates of average marginal effects and their $95 \%$ confidence intervals. ${ }^{5}$ Since coefficients in multinomial logistic models are estimated in $\log$ odds, average marginal effects were calculated for each category of the depended variable. These are easier to interpret as they represent the probability for each employment category dependent on the binary childcare variable, i.e. the average change in probability for the respective category among all observations in the sample. ${ }^{6}$ As coefficients of the control variables cannot be interpretable meaningfully after entropy balancing, only the average marginal effects of the childcare estimates are presented. For all estimated models, average marginal effects, standard errors, number of observations, number of counties with abovemedian childcare, and total numbers of counties are reported in the Online Appendix.

Figure 1 shows the average marginal effects of above-median childcare provision, provided as full-time or part-time places, on mothers' employment in East and West Germany. For West German mothers with a first or second birth (subgraph 1, column 1), higher coverage levels were associated with lower levels of non-employment and marginal employment participation. Conversely, the relationship with part-time and full-time employment was significantly positive, with a particularly pronounced link with part-time employment. With above-median childcare provision, the likelihood of mothers working part-time was 6 percentage points higher compared to mothers in counties with below-median childcare provision. Similarly, the likelihood of full-time employment was 3 percentage points higher in counties with higher childcare coverage levels (see Table A3 in the Online Appendix).

Distinguishing between West German mothers with first and second births (Figure 1, subgraph 2 and 3) illustrates that the relationship between higher childcare coverage levels and maternal employment varies for first and second births. For part-time employment, the estimate was more pronounced and only significant for first births. In contrast, the estimate for full-time employment was larger and significant only for second births. Overall, the result for West Germany corresponded to Hypothesis 1, assuming a positive association between higher childcare levels and maternal employment.

Conversely, for the much smaller sample of East German mothers, employment differences between mothers with childcare provision above or below the median childcare ratio seemed to 
be less distinct. With estimates that were small in magnitude and statistically insignificant, the results did not support Hypothesis 1.

\section{$>$ Figure $1<$}

Figure 2 illustrates how the relationship between childcare and maternal employment differs for West German mothers with a university or college degree (high), vocational training (medium), or a lower qualification (low) (see also Table A4 in the Online Appendix). Subgraph 1 shows the results for a model, in which no distinction is made between mothers with first or second births, but which includes all. For all three educational groups of mothers above-median childcare provision was negatively associated with non-employment or marginal employment. Conversely, estimates of part-time employment were positive, but statistically significant only for medium- and low-skilled mothers. Similarly, estimates for full-time employment were positive, but statistically insignificant.

The further differentiation between first and second births showed that higher capacities were particularly important for better-educated mothers, but that educational disparities in the observed relationship differed for first and second births (subgraph 2 and 3). For medium- and low-skilled mothers, results revealed positive relationships with part-time employment, which were more pronounced and statistically significant for second births. For medium- and highly skilled mothers, however, the estimators for full-time employment were larger and statistically significant for a second birth. For highly skilled mothers, the effects for part-time employment after a first birth were also larger, albeit statistically insignificant. The results therefore suggest that in West Germany childcare is particularly important for better-educated mothers, providing support for Hypothesis 2.

\section{$>$ Figure $2<$}

Figure 3 shows the results for the same models for East Germany, however, these only distinguish between highly and moderately educated mothers due to low observational numbers for low-skilled mothers. For the models that do not distinguish between first and second birth, the results showed again very small and mostly insignificant effects (subgraph 1). The further distinction between first and second births also did reveal comparatively small employment differences. For highly skilled mothers with a first birth, was the relationship between childcare and part-time employment positive and statistically significant. Conversely, and surprisingly, the relationship with full-time employment was negative. For medium-skilled mothers, the results suggested negative associations between childcare and maternal employment, however 
effects were small and predominantly insignificant. These mixed results therefore did not provide strong support for Hypothesis 2, which assumed a stronger link between childcare provision and employment among mothers with a higher level of education. Instead, the results provided tentative evidence for Hypothesis 3, presuming less pronounced educational disparities in maternal employment for East Germany.

\section{$>$ Figures $3<$}

In the final step, a logistic regression was estimated to examine the relationship between fulltime childcare and full-time employment for all educational groups in East and West Germany (Figure 4). Similar to the above findings, which considered full-time and part-time places together, higher levels of full-time childcare seemed to be particularly important for all West German mothers with a second birth (row 1). Thus, for West Germany, the results support the initial assumption (H1) that higher levels of childcare, especially when full-time, are positively linked to full-time employment of mothers.

Differentiating West German mothers according to their educational background (row 2-4), showed clear educational disparities in the relationship between full-time childcare and fulltime employment. For highly- and medium-skilled West German mothers, higher childcare capacities were positively linked to full-time employment. For the former, however, the effects were larger and statistically significant for both first and second births. For medium-skilled mothers the results were statistically significant only for second births. The results for lowskilled mothers showed a negative but insignificant relationship. However, this finding is based on a small number of low-skilled mothers working full-time, which did not allow for a separate analysis for first and second births. In summary, results of full-time childcare in West Germany indicated a stronger association between childcare and employment for mothers with higher educational attainment $(H 2)$.

For the two educational groups of East German mothers, the results showed again only a few group-specific differences in the relationship between childcare and full-time employment. At the same time, the results differed less between first and second births. For highly educated mothers, the relationship between childcare and full-time employment was again negative, but only statistically significant for first births. For mothers with vocational training, effects were positive and statistically significant for both, but especially for first births. Since the results only show a positive correlation between higher childcare capacities and maternal full-time employment for some of the East German mothers examined, the findings only partially 
supported hypotheses 1 and 2. Instead, the results seem to support hypothesis 3, assuming educational disparities in maternal employment to be less distinct in East Germany.

\section{$>$ Figure $4<$}

\section{Sensitivity checks}

To ensure that the chosen upper and lower limits of part-time and full-time employment did not drive the results, all models were re-estimated with different class limits (part-time as 15-32 or 15-36 hours). Secondly, women with births prior to the parental leave reform in 2007 were excluded. Similarly, all models were re-estimated excluding mothers with a child over the age of one in August 2013 to ensure that results are not driven exclusively by the introduction of the legal entitlement to a childcare place. Lastly, it was tested whether further controls, such as a dummy indicating current pregnancy and annual average weekly working hours for women in East and West Germany alter the results. The findings are robust to all sensitivity checks. Table A5 in the appendix presents results obtained from multinomial regression estimations without entropy balancing. The results show similar patterns and therefore confirm the above findings. However, similar to the common support assumption of propensity score matching techniques estimates from entropy balancing refer to a subpopulation of the sample. Thus, the estimation of causal effects depends on whether all conditioning variables that simultaneously determine selection into regions with high childcare coverage and maternal employment can be taken into account. Although the results rely on a large number of observables, the obtained results might not be causal if mothers from counties with varying childcare provision still differ in unobserved characteristics. Additionally, estimating county-level fixed-effects models using a linear or categorical childcare measure did not reveal a significant relationship for East or West Germany due to the comparatively small within-county level variation in annual childcare coverage observed for each mothers with a child under three. ${ }^{7}$ Lastly, all models were reestimated for mothers with a youngest child aged between three and six. The results revealed no significant effects and, hence, suggested that no general employment trend is driving the presented results.

\section{Discussion and Conclusion}

This study provides evidence on educational disparities in the relationship between higher childcare coverage levels and maternal employment in the context of East and West Germany. For West Germany, higher childcare levels were positively linked to maternal employment, 
whereas the relationship with non-employment or marginal employment was negative. The positive relationship was driven by part-time employment among medium- and low-skilled mothers, and by full-time employment among medium- and highly skilled mothers. Larger and statistically significant estimates after second births indicate that childcare may be more relevant when family formation is likely to be completed. However, the equally larger estimates for part-time employment of highly skilled mothers indicate that for this very work-oriented group of mothers, higher childcare levels may be already relevant after a first birth. Similarly, the positive associations between full-time childcare and full-time employment were limited to highly- and medium-skilled West German mothers. This association was statistically significant only for second births in the case of mothers with vocational training, but for both first and second births in the case of highly skilled mothers. Again, this illustrates the special importance of childcare for high-skilled mothers.

In the context of higher childcare levels in East Germany, employment differences were less pronounced between regions with above and below-median childcare provision. For the much smaller sample of highly skilled mothers, higher childcare coverage levels were positively associated with more part-time, but less full-time employment only after first births. For fulltime childcare, results were positive and statistically significant for mothers with vocational training, particularly for first births. Conversely, for highly skilled mothers with a first child the relationship was significantly negative. Hence, the results suggest that the overall significantly higher childcare coverage level in East Germany is responsible for comparatively small differences in maternal employment. In contrast to West Germany, capacity differences at a higher expansion level seem to affect mothers with a vocational degree in particular.

The observed educational differences between childcare and maternal employment are consistent with recent trends, according to which mothers with at least vocational training have become more likely to use formal childcare (Stahl and Schober, 2018). Conversely, low-skilled mothers, who have so far adhered to more traditional work-care norms (Zoch and Schober, 2018) and showed a comparatively weaker attachment to the labour market (Konietzka and Kreyenfeld, 2010), seem to continue to work predominantly in part-time or marginal employment. Therefore, from a broader perspective, the results point to the different reasons for low-skilled mothers not using childcare. These may include more traditional work-care norms or formal as well as informal access barriers, which favour particularly highly educated parents when childcare places are still limited. 
For East Germany, the negative but mostly insignificant employment estimates for highly educated mothers contradict previous family policy evaluations that found particularly pronounced employment effects among these mothers (Gangl and Ziefle, 2015). The results might point to persistent labour market disparities between East and West Germany. For example, East Germany's large number of (very) small firms provides fewer career options for women than it is the case in West Germany. Together with persistently lower wages, these poorer job prospects may have reduced the employment orientation of mothers with very young children. Similarly, an increasingly critical perception of persistently higher child-teacher ratios and larger group sizes in East Germany might have reduced the cultural acceptance of childcare services for very young children, and thus, maternal (full-time) employment, particularly among highly educated mothers. This is supported by recent findings, showing a significantly negative association between childcare services with larger group sizes and maternal employment participation only for mothers in East Germany (Schober and Spieß, 2015). From a wider perspective, a reduced full-time employment orientation among highly educated mothers would be in line with findings on the positive association between higher childcare coverage levels and more traditional gender ideologies towards maternal employment and nonparental care among college-educated mothers in East Germany (Zoch and Schober, 2018).

The particularly pronounced results for mothers with a second child - mostly in West Germany - suggest that childcare provision might not significantly alter mothers' employment behaviour if they still plan to have more children, and thus, to interrupt employment in the future. As mothers might expect employers to be averse to a temporary return to employment, they may perceive this as less beneficial than a single but longer employment interruption. Consequently, childcare is likely to become important only after family planning is complete, particularly with respect to full-time employment. This is supported by previous research showing a more pronounced and persistent two-child norm (Diabaté and Ruckdeschel, 2017), a tight spacing of two to four years between a first and second child (Kreyenfeld, 2008), as well as a more pronounced association between childcare and shorter employment interruption durations among West German mothers with a second birth (Zoch and Hondralis, 2017). Alternatively, the results may suggest that mothers with only one child might have greater problems finding a childcare slot as it has become common practice to give priority access to children with an older sibling in the institution (Stahl et al., 2018).

Overall, the findings indicate that above-median childcare provision is significantly associated with maternal employment, with more pronounced associations for more educated mothers, especially in West Germany. However, some important limitations need to be 
considered. Some of the subgroup findings are based on a small number of counties with abovemedian childcare provision. Hence, results should be interpreted with caution. Similarly, small sample sizes, particularly for low-skilled mothers, did not allow for further subsample analyses. By applying entropy balancing and exploiting variation in county-level childcare coverage, as well as a wide range of individual, household and county-level conditioning variables, the study tries to account for potential sources of bias. Yet, the risk of bias remains due to other unobserved characteristics, such as parents' information on childcare availability, or work-care norms, as well as the lack of available longitudinal, nation-wide data on formal childcare quality, costs or access conditions, which may correlate with childcare expansion, childcare take-up and maternal employment. Consequently, the investigation of possible direct and indirect mechanisms is not possible and must therefore be subject of future research.

However, despite these limitations, the findings align with previous studies highlighting the importance of public childcare for maternal employment, particularly in regions with previously low levels of childcare coverage (e.g., Brilli et al., 2016). The study finds that abovemedian childcare provision seems to be of particular importance to mothers with higher education levels and after second births. In addition, the study emphasises the importance of full-time childcare provision for full-time employment in both East and West Germany and, thereby, points to important educational disparities in maternal employment. Thus, the study expands upon previous research that often failed to distinguish between the provisions of childcare in general, and full-time childcare in particular, as well as differentiating between mothers with different educational backgrounds and between first and second births. Given the observed Matthew effect, the results suggest that in order to increase the employment participation of all women, the expansion of accessible and affordable childcare services, particularly full-time and preferably of high quality, is still of crucial importance. 
${ }^{1}$ Childcare coverage levels between 33 percent and 49 percent have been reached in Finland, Italy, Spain, Slovenia, Belgium, and France, while provision rates exceed 50 percent only in Denmark, Netherlands, Sweden, Luxembourg, and Portugal (European Commission, 2018).

${ }^{2}$ Marginal employment, or so-called 'mini-jobs', are defined by a maximum income of 400 Euros per month (after 2013450 Euros) and no social insurance contributions for employees.

3 The method has been applied in comparable analyses of the influence of afternoon care for primary school children on maternal employment (Gambaro et al., 2019).

${ }^{4}$ Although childcare coverage has increased tremendously, parental demand still exceeds the supply in East and West Germany, which is constantly monitored (BMFSJ 2015). Hence, childcare attendance ratios are considered as a measure of supply rather than demand, which is in line with all previous studies on Germany.

${ }^{5}$ Intervals crossing the vertical 0-line indicate statistically insignificant effects.

${ }^{6}$ The discrete differences between mothers with below- and above-median childcare provision, that is the discrete marginal effects, for all four individual employment categories sum up to zero, so that there is no "classical" reference category. Instead, each effect must be compared to the effects on the other categories.

${ }^{7}$ Among West German mothers, within-childcare variation is only about 2.6 compared to a between-childcare variation of 7.3. For East Germany, a within-childcare variation (2.1) and between-variation (7.6) is observed. 


\section{References}

Andronescu, C. G. and Carnes, M. E. (2015) 'Value coalitions and policy change: The impact of gendered patterns of work, religion and partisanship on childcare policy across German states', Journal of European Social Policy 25(2): 159-74.

Becker, G. S. (2009) Human Capital: A Theoretical and Empirical Analysis, with Special Reference to Education. Chicago, IL: University of Chicago Press.

Bonin, H., Fichtl, A., Rainer, H., Spieß, C. K., Stichnoth, H. and Wrohlich, K. (2013) 'Lehren für die Familienpolitik - Zentrale Resultate der Gesamtevaluation familienbezogener Leistungen', ifo Schnelldienst 66(18): 22-30.

Brilli, Y., Del Boca, D. and Pronzato, C. D. (2016) 'Does child care availability play a role in maternal employment and children's development?: Evidence from Italy', Rev Econ Household 14(1): 27-51.

Bundesministerium für Familie, Senioren, Frauen und Jugend (BMFSFJ) (2015) 'Fünfter Bericht zur Evaluation des Kinderförderungsgesetzes'. Berlin: BMFSFJ.

Caliendo, M. and Kopeinig, S. (2008) 'Some Practical Guidance For the Implementation of Propensity Score Matching', Journal of Economic Surveys 22(1): 31-72.

Chaudry, A., Henly, J. and Meyers, M. (2010) Conceptual Frameworks for Child Care DecisionMaking. Washington, DC.

Del Boca, D. and Vuri, D. (2007) 'The mismatch between employment and child care in Italy: The impact of rationing.', Journal of Population Economics 20(4): 805-32.

Diabaté, S. and Ruckdeschel, K. (2017) 'Am besten ein Mädchen und ein Junge? Geschwisterleitbilder in Deutschland', Bevölkerungsforschung Aktuell 38(2): 2-10.

European Commission (2018) 'KOM/2018/0273'. Brussel: European Commission. http://www.ipex.eu/IPEXL-WEB/dossier/document/COM20180273.do.

Federal Statistical Office (2018) 'Kindertagesbetreuung regional'. Wiesbaden: Federal Statistical Office Germany. https://www.destatis.de/GPStatistik/receive/DESerie_serie_00000386.

Gambaro, L., Marcus, J. and Peter, F. (2019) 'School entry, afternoon care, and mothers' labour supply', Empirical Economics: [online first: 2018-06-07].

Gangl, M. and Ziefle, A. (2015) 'The Making of a Good Woman: Extended Parental Leave Entitlements and Mothers' Work Commitment in Germany', American Journal of Sociology 121(2): 511-63.

Haan, P. and Wrohlich, K. (2011) 'Can child care policy encourage employment and fertility?', Labour Economics 18(4): 498-512.

Hainmueller, J. (2012) 'Entropy Balancing for Causal Effects: A Multivariate Reweighting Method to Produce Balanced Samples in Observational Studies.', Political Analysis 20(01): 25-46.

Havnes, T. and Mogstad, M. (2011) 'Money for nothing?: Universal child care and maternal employment', Journal of Public Economics 95(11-12): 1455-65.

Konietzka, D. and Kreyenfeld, M. (2010) 'The growing educational divide in mothers' employment: an investigation based on the German micro-censuses 1976-2004.', Work, Employment \& Society 24(2): 260-78.

Kreyenfeld, M. (2008) 'Das zweite Kind in Ostdeutschland: Aufschub oder Verzicht?', in I. Cassens, M. Luy and R. Scholz (eds) Die Bevölkerung in Ost-und Westdeutschland: Demografische, gesellschaftliche und wirtschaftliche Entwicklungen seit der Wende., pp. 100-23. Wiesbaden: VS Verlag.

Kreyenfeld, M. and Hank, K. (2000) 'Does the availability of child care influence the employment of mothers?: Findings from western Germany', Population Research and Policy Review 19(4): 31737.

Meyers, M. K. and Jordan, L. P. (2006) 'Choice and Accommodation in Parental Child Care Decisions', Community Development 37(2): 53-70. 
Mincer, J. and Polachek, S. (1974) 'Family Investments in Human Capital: Earnings of Women', Journal of Political Economy 82(2): S76-S108.

Morrissey, T. W. (2017) 'Child care and parent labor force participation: a review of the research literature.', Review of Economics of the Household 15: 1-24.

Pavolini, E. and van Lancker, W. (2018) 'The Matthew effect in childcare use: A matter of policies or preferences?', Journal of European Public Policy 25(6): 878-93.

Rosenfeld, R. A., Trappe, H. and Gornick, J. C. (2004) 'Gender and Work in Germany: Before and After Reunification’, Annu. Rev. Sociol. 30(1): 103-24.

Schmitz, S., Spieß, K. C. and Stahl, J. F. (2017) 'Day Care Centers: Family Expenditures Increased Significantly at Some Points between 1996 and 2015', DIW Economic Bulletin 42: 411-23.

Schober, P. S. and Spieß, C. K. (2015) 'Local Day Care Quality and Maternal Employment: Evidence From East and West Germany', Journal of Marriage and Family 77(3): 712-29.

Spieß, C. K., Berger, E. M. and Groh-Samberg, O. (2008) 'Overcoming Disparities and Expanding Access to Early Childhood Services in Germany: Policy Considerations and Funding Options.'. Florence: UNICEF Innocenti Research Centre(IWP-2008-03). http://www.unicefirc.org/publications/pdf/iwp_2008_03_eng.pdf.

Stahl, J. F. and Schober, P. S. (2018) 'Convergence or divergence?: Educational discrepancies in work-care arrangements of mothers with young children in Germany', Work, employment and society 32(4): 629-49.

Stahl, J. F., Schober, P. S. and Spiess, C. K. (2018) 'Parental socio-economic status and childcare quality: Early inequalities in educational opportunity?', Early Childhood Research Quarterly 44: 304-17.

Steiber, N. and Haas, B. (2012) 'Advances in explaining women's employment patterns', SocioEconomic Review 10(2): 343-67.

Stets, J. E. and Burke, P. J. (2000) 'Identity Theory and Social Identity Theory', Social Psychology Quarterly 63(3): 224-237.

Stuart, E. A. (2010) 'Matching methods for causal inference: A review and a look forward', Statistical science : a review journal of the Institute of Mathematical Statistics 25(1): 1-21.

van Lancker, W. and Ghysels, J. (2016) 'Explaining patterns of inequality in childcare service use across 31 developed economies: A welfare state perspective', International Journal of Comparative Sociology 57(5): 310-37.

Wagner, G. G., Frick, J. R. and Schupp, J. (2007) 'The German Socio-Economic Panel Study (SOEP) - Scope, Evolution and Enhancements.', Schmollers Jahrbuch 127(1): 139-69.

Zoch, G. and Hondralis, I. (2017) 'The Expansion of Low-Cost, State-Subsidized Childcare Availability and Mothers' Return-to-Work Behaviour in East and West Germany’, European Sociological Review 33(5): 693-707.

Zoch, G. and Schober, P. S. (2018) 'Public Child-Care Expansion and Changing Gender Ideologies of Parents in Germany', Journal of Marriage and Family 80(4): 1020-39. 


\section{Figures}

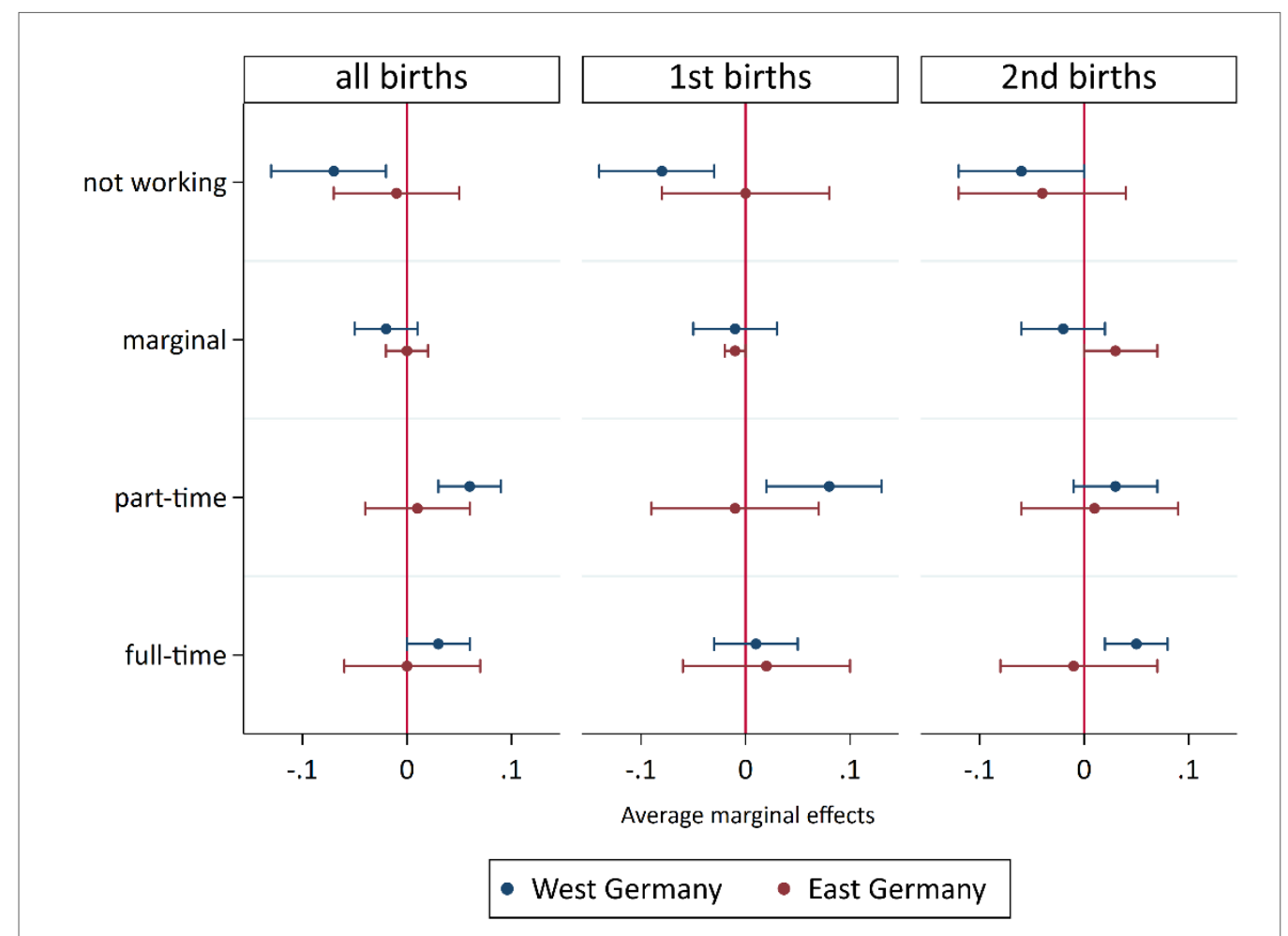

Figure 1. Average marginal effects for above-median childcare on maternal employment in East and West Germany by all, first and second births (multinomial logistic regression models, SOEP v33, 2007-2016).

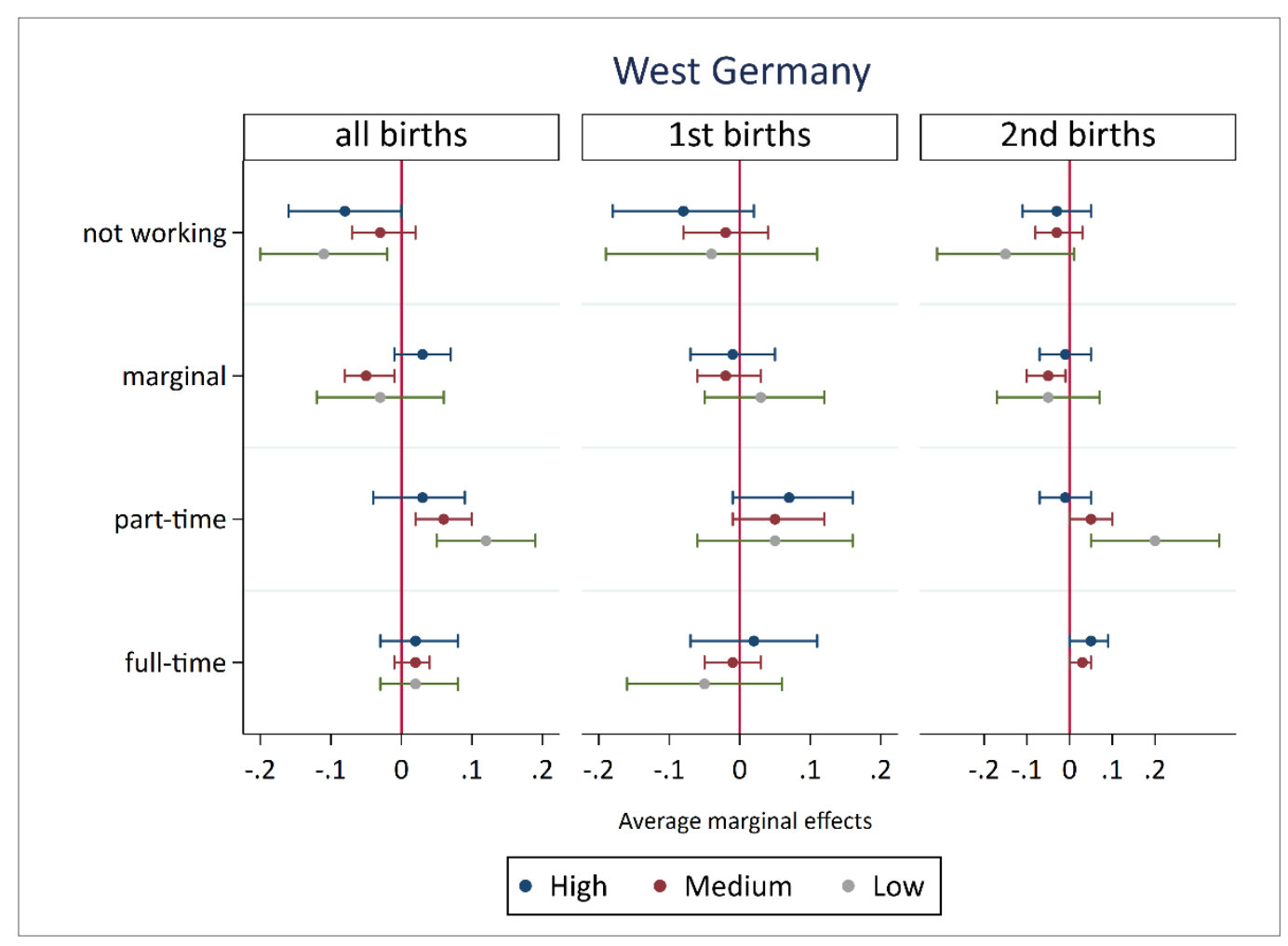

Figure 2. Average marginal effects for above-median childcare on maternal employment in West Germany by mothers' educational attainment and birth (multinomial logistic regression models, SOEP v33, 2007-2016).

Note: Too few observations for low-skilled mothers to distinguish between part-time and full-time among mothers with a second birth. 


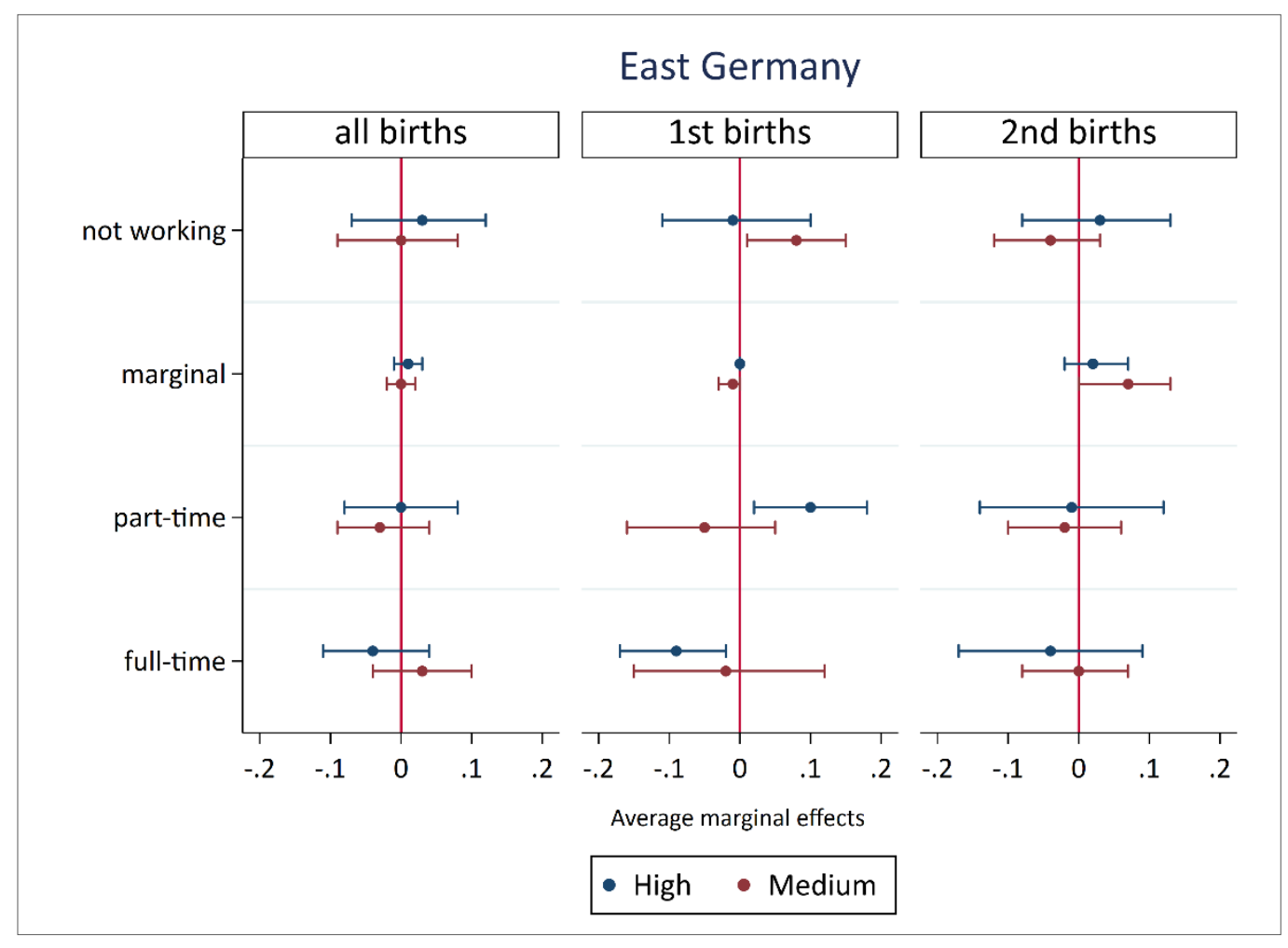

Figure 3. Average marginal effects for above-median childcare on maternal employment in East Germany by mothers' educational attainment and birth (multinomial logistic regression models, SOEP v33, 2007-2016).

Note: Too few observations to estimate separate models for low-skilled mothers.

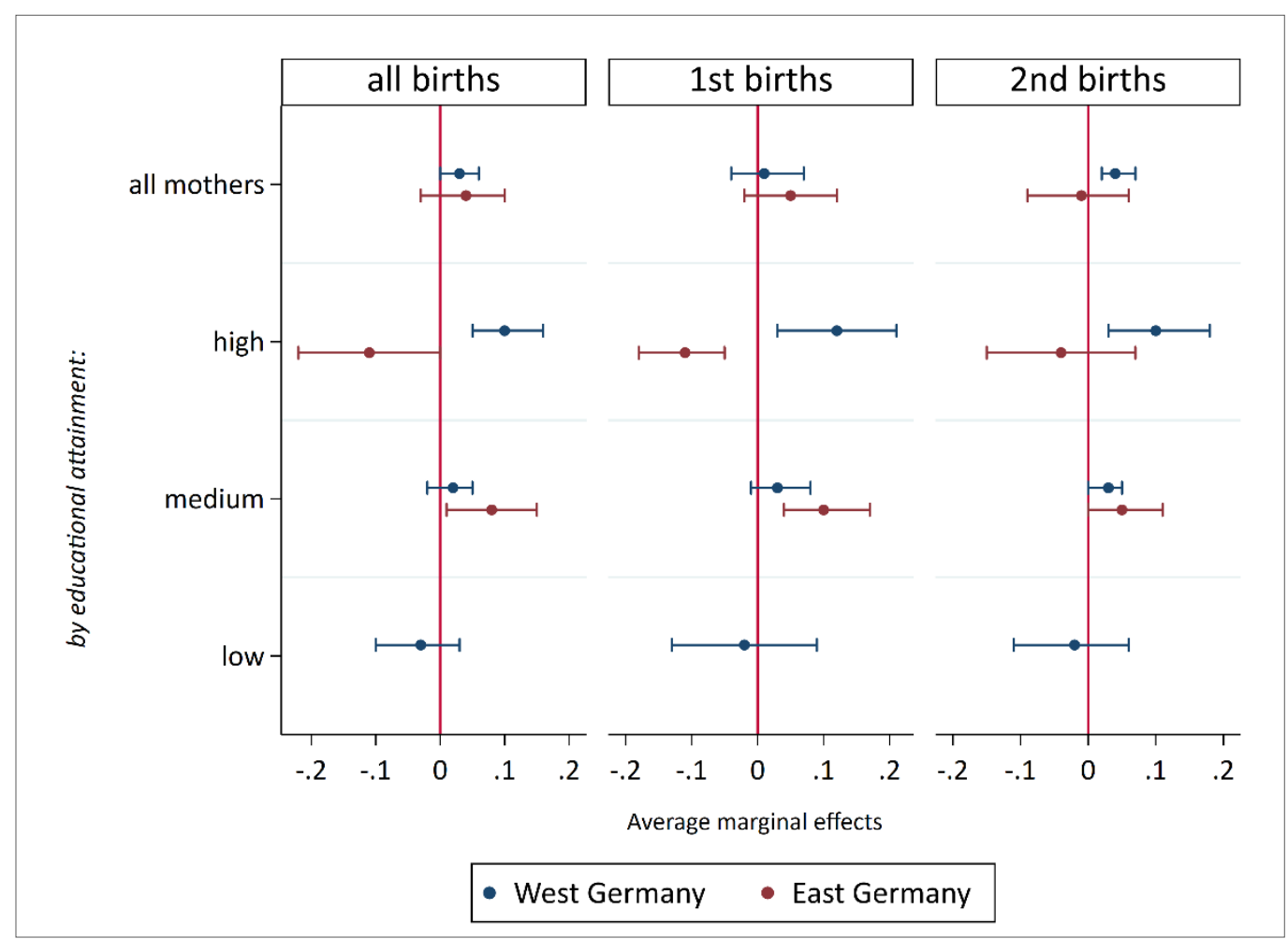

Figure 4 Average marginal effects for above-median full-time childcare on full-time employment by mothers' educational attainment and birth in East and West Germany (logistic regression models, SOEP v33, 2007-2016)

Note: Too few observations for low-skilled mothers to distinguish between first and second births among West German mothers and to estimate separate models for low-skilled in East Germany 


\section{Appendix}
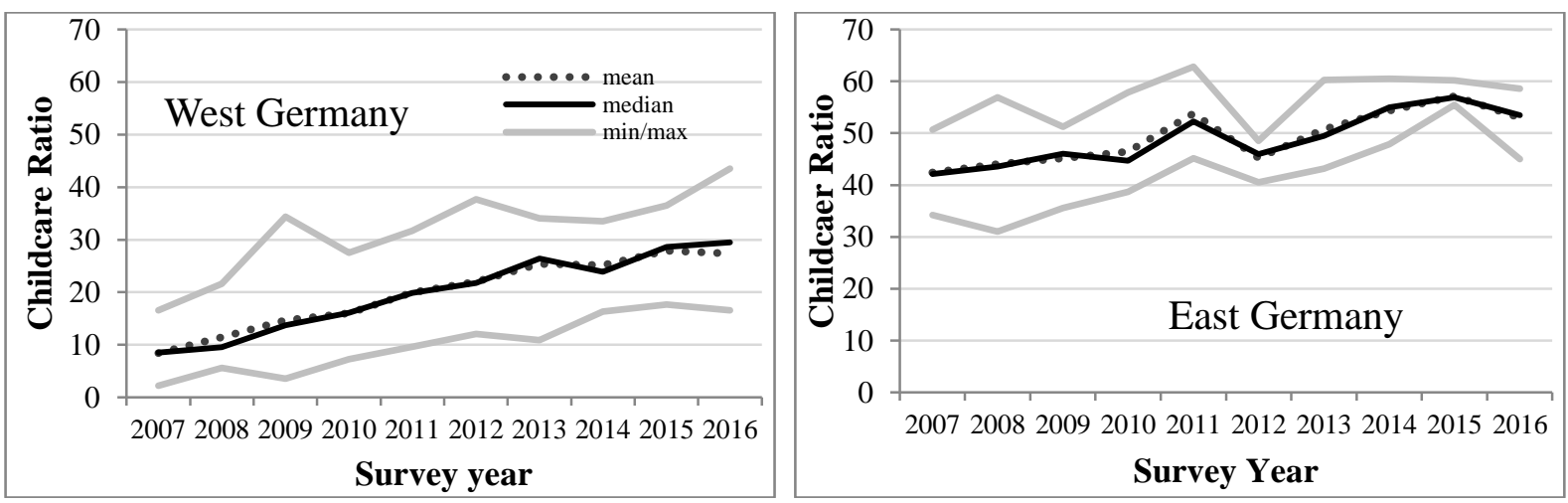

Figure A5 Childcare attendance ratios for under-three-year-olds (in \%)
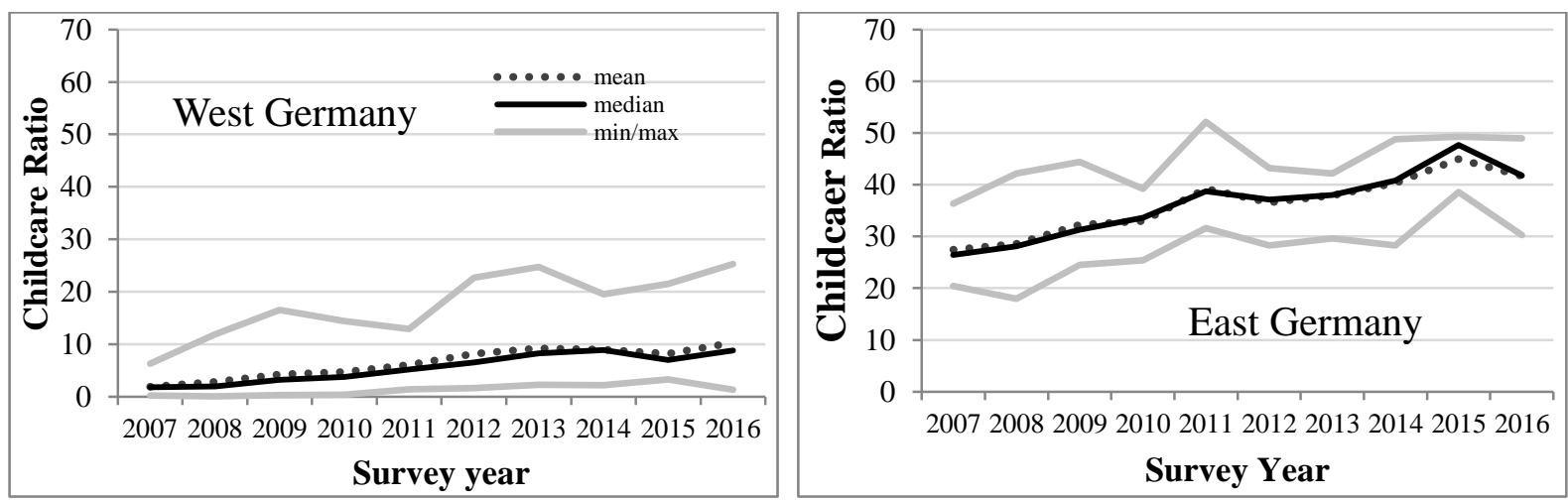

Figure A6 Full-time childcare attendance ratios for under-three-year-olds (in \%) 
Table A1 Summary statistics for maternal employment

\begin{tabular}{|c|c|c|c|c|c|c|c|c|c|c|c|c|c|c|c|c|}
\hline & \multicolumn{8}{|c|}{ Above-median childcare } & \multicolumn{8}{|c|}{ Below-median childcare } \\
\hline & \multirow{2}{*}{\multicolumn{2}{|c|}{$\begin{array}{c}\text { All } \\
\text { mothers }\end{array}$}} & \multirow{2}{*}{\multicolumn{4}{|c|}{$\begin{array}{c}\text { Education } \\
\text { Medium }\end{array}$}} & \multirow{2}{*}{\multicolumn{2}{|c|}{ Low }} & \multirow{2}{*}{\multicolumn{2}{|c|}{$\begin{array}{c}\text { All } \\
\text { mothers }\end{array}$}} & \multicolumn{6}{|c|}{ Education } \\
\hline & & & & & & & & & & & \multirow{2}{*}{\multicolumn{2}{|c|}{$\begin{array}{c}\text { High } \\
\text { mean/sd }\end{array}$}} & \multicolumn{2}{|c|}{ Medium } & \multicolumn{2}{|c|}{ Low } \\
\hline & \multicolumn{2}{|c|}{ mean/sd } & \multicolumn{2}{|c|}{ mean/sd } & \multicolumn{2}{|c|}{ mean/sd } & \multicolumn{2}{|c|}{ mean/sd } & \multicolumn{2}{|c|}{ mean/sd } & & & mea & $\mathrm{a} / \mathrm{sd}$ & & \\
\hline \multicolumn{17}{|c|}{ West Germany } \\
\hline \multicolumn{17}{|c|}{$1^{\text {st }}$ and $2^{\text {nd }}$ births } \\
\hline Not working & 0.54 & 0.50 & 0.49 & 0.50 & 0.56 & 0.50 & 0.64 & 0.48 & 0.58 & 0.49 & 0.52 & 0.50 & 0.56 & 0.50 & 0.81 & 0.40 \\
\hline Marginal & 0.10 & 0.30 & 0.07 & 0.25 & 0.12 & 0.32 & 0.14 & 0.34 & 0.15 & 0.36 & 0.10 & 0.31 & 0.17 & 0.37 & 0.13 & 0.33 \\
\hline Part-time & 0.26 & 0.44 & 0.29 & 0.45 & 0.25 & 0.43 & 0.14 & 0.35 & 0.20 & 0.40 & 0.27 & 0.44 & 0.20 & 0.40 & 0.04 & 0.19 \\
\hline Full-time & 0.11 & 0.31 & 0.15 & 0.36 & 0.07 & 0.26 & 0.08 & 0.27 & 0.07 & 0.26 & 0.11 & 0.31 & 0.06 & 0.25 & 0.03 & 0.17 \\
\hline $\mathrm{N}$ & \multicolumn{2}{|c|}{2276} & \multicolumn{2}{|c|}{878} & \multicolumn{2}{|c|}{1222} & \multicolumn{2}{|c|}{176} & \multicolumn{2}{|c|}{2148} & \multicolumn{2}{|c|}{488} & \multicolumn{2}{|c|}{1449} & \multicolumn{2}{|c|}{211} \\
\hline \multicolumn{17}{|l|}{$1^{\text {st }}$ births } \\
\hline Not working & 0.52 & 0.50 & 0.46 & 0.50 & 0.54 & 0.50 & 0.63 & 0.49 & 0.58 & 0.49 & 0.56 & 0.50 & 0.55 & 0.50 & 0.79 & 0.41 \\
\hline Marginal & 0.09 & 0.29 & 0.07 & 0.25 & 0.11 & 0.31 & 0.12 & 0.33 & 0.12 & 0.33 & 0.07 & 0.26 & 0.14 & 0.35 & 0.12 & 0.33 \\
\hline Part-time & 0.27 & 0.45 & 0.30 & 0.46 & 0.27 & 0.45 & 0.13 & 0.34 & 0.19 & 0.40 & 0.22 & 0.42 & 0.21 & 0.41 & 0.04 & 0.19 \\
\hline Full-time & 0.12 & 0.33 & 0.17 & 0.38 & 0.08 & 0.28 & 0.12 & 0.33 & 0.10 & 0.30 & 0.14 & 0.35 & 0.10 & 0.30 & 0.05 & 0.21 \\
\hline $\mathrm{N}$ & \multicolumn{2}{|c|}{976} & \multicolumn{2}{|c|}{397} & \multicolumn{2}{|c|}{495} & 8 & & & & & & 6 & 3 & 10 & \\
\hline $2^{\text {nd }}$ births & & & & & & & & & & & & & & & & \\
\hline Not working & 0.56 & 0.50 & 0.10 & 0.50 & 0.57 & 0.50 & 0.65 & 0.48 & 0.57 & 0.49 & 0.49 & 0.50 & 0.57 & 0.49 & 0.82 & 0.39 \\
\hline Marginal & 0.11 & 0.31 & 0.07 & 0.26 & 0.12 & 0.33 & 0.15 & 0.36 & 0.17 & 0.38 & 0.13 & 0.33 & 0.19 & 0.40 & 0.13 & 0.34 \\
\hline Part-time & 0.25 & 0.43 & 0.28 & 0.45 & 0.24 & 0.42 & 0.15 & 0.36 & 0.21 & 0.40 & 0.30 & 0.46 & 0.19 & 0.40 & 0.04 & 0.19 \\
\hline Full-time & 0.09 & 0.29 & 0.14 & 0.34 & 0.07 & 0.25 & 0.04 & 0.21 & 0.05 & 0.21 & 0.08 & 0.27 & 0.04 & 0.20 & 0.01 & 0.10 \\
\hline $\mathrm{N}$ & 13 & & 4 & & & & 9 & & & & & & 80 & & 10 & \\
\hline
\end{tabular}

\section{East Germany}

\section{$1^{\text {st }}$ and $2^{\text {nd }}$ births}

$\begin{array}{lllllllll}\text { Not working } & 0.48 & 0.50 & 0.39 & 0.49 & 0.51 & 0.50 & 0.70 & 0.46\end{array}$

$\begin{array}{lllllllll}\text { Marginal } & 0.03 & 0.17 & 0.02 & 0.15 & 0.03 & 0.18 & 0.02 & 0.15\end{array}$

$\begin{array}{llllllllll}\text { Part-time } & 0.20 & 0.40 & 0.23 & 0.42 & 0.19 & 0.39 & 0.14 & 0.35\end{array}$

$\begin{array}{llllllllll}\text { Full-time } & 0.29 & 0.45 & 0.36 & 0.48 & 0.27 & 0.44 & 0.14 & 0.35\end{array}$

$\mathrm{N}$

$$
628
$$

219

366

43

\begin{tabular}{llllllll}
0.50 & 0.50 & 0.42 & 0.49 & 0.53 & 0.50 & 0.77 & 0.43 \\
0.03 & 0.18 & 0.01 & 0.12 & 0.04 & 0.21 & 0.06 & 0.24 \\
$\mathbf{0 . 2 4}$ & 0.43 & 0.25 & 0.43 & $\mathbf{0 . 2 5}$ & 0.43 & 0.11 & 0.32 \\
$\mathbf{0 . 2 3}$ & 0.42 & 0.32 & 0.47 & $\mathbf{0 . 1 7}$ & 0.38 & 0.06 & 0.24 \\
\multicolumn{2}{c}{705} & \multicolumn{2}{c}{288} & \multicolumn{2}{c}{288} & \multicolumn{2}{c}{35}
\end{tabular}

$1^{\text {st }}$ births

$\begin{array}{lllllllll}\text { Not working } & 0.46 & 0.50 & 0.35 & 0.48 & 0.51 & 0.50 & 0.62 & 0.50\end{array}$

$\begin{array}{lllllllll}\text { Marginal } & 0.01 & 0.08 & 0.00 & 0.00 & 0.01 & 0.11 & 0.00 & 0.00\end{array}$

$\begin{array}{lllllllll}\text { Part-time } & 0.18 & 0.38 & 0.21 & 0.41 & 0.16 & 0.36 & 0.15 & 0.37\end{array}$

$\begin{array}{lllllllll}\text { Full-time } & 0.36 & 0.48 & 0.44 & 0.50 & 0.33 & 0.47 & 0.23 & 0.43\end{array}$

$$
\begin{array}{llll}
301 & 103 & 172 & 26
\end{array}
$$

\begin{tabular}{cccccccc}
0.45 & 0.50 & 0.42 & 0.50 & 0.44 & 0.50 & 0.80 & 0.42 \\
$\mathbf{0 . 0 4}$ & 0.19 & 0.01 & 0.09 & $\mathbf{0 . 0 6}$ & 0.23 & 0.10 & 0.32 \\
$\mathbf{0 . 2 4}$ & 0.43 & 0.22 & 0.42 & $\mathbf{0 . 2 6}$ & 0.44 & 0.00 & 0.00 \\
$\mathbf{0 . 2 8}$ & 0.45 & 0.35 & 0.48 & $\mathbf{0 . 2 4}$ & 0.43 & 0.10 & 0.32 \\
\multicolumn{2}{c}{280} & \multicolumn{2}{c}{112} & \multicolumn{2}{c}{158} & \multicolumn{2}{c}{10}
\end{tabular}

$2^{\text {nd }}$ births

$\begin{array}{lllllllll}\text { Not working } & 0.50 & 0.50 & 0.42 & 0.50 & 0.52 & 0.50 & 0.82 & 0.39\end{array}$

$\begin{array}{lllllllll}\text { Marginal } & 0.05 & 0.22 & 0.04 & 0.20 & 0.05 & 0.22 & 0.06 & 0.24\end{array}$

$\begin{array}{lllllllll}\text { Part-time } & 0.22 & 0.42 & 0.25 & 0.43 & 0.21 & 0.41 & 0.12 & 0.33\end{array}$

$\begin{array}{lllllllll}\text { Full-time } & 0.23 & 0.42 & 0.28 & 0.45 & 0.22 & 0.42 & 0.00 & 0.00\end{array}$

$\begin{array}{lllll}\mathrm{N} & 327 & 116 & 194 & 17\end{array}$

\begin{tabular}{llllllll}
0.53 & 0.50 & 0.42 & 0.50 & 0.59 & 0.49 & 0.76 & 0.44 \\
0.03 & 0.17 & 0.02 & 0.13 & 0.04 & 0.19 & 0.04 & 0.20 \\
0.25 & 0.43 & 0.27 & 0.44 & 0.25 & 0.43 & 0.16 & 0.37 \\
0.19 & 0.39 & 0.30 & 0.46 & $\mathbf{0 . 1 2}$ & 0.33 & 0.04 & 0.20 \\
425 & \multicolumn{2}{c}{176} & \multicolumn{2}{c}{224} & \multicolumn{2}{c}{25}
\end{tabular}

Note: Bold figures indicate significant mean differences between mothers with above and below-median childcare before matching (t-test) Source: SOEP v33 (2007-2016). 
Table A2 Summary statistics for selected conditioning variables before and after entropy balancing (first and second births combined)

\begin{tabular}{|c|c|c|c|c|c|c|c|c|c|c|}
\hline \multirow{4}{*}{ Variable } & \multicolumn{5}{|c|}{ West Germany } & \multicolumn{5}{|c|}{ East Germany } \\
\hline & \multicolumn{3}{|c|}{ Mean } & \multirow{2}{*}{\multicolumn{2}{|c|}{$\begin{array}{c}\text { Standard. bias (\%) } \\
\begin{array}{c}\text { Below-median } \\
\text { childcare }\end{array} \\
\end{array}$}} & \multicolumn{3}{|c|}{ Mean } & \multirow{2}{*}{\multicolumn{2}{|c|}{$\begin{array}{c}\text { Standard. Bias (\%) } \\
\begin{array}{c}\text { Below-median } \\
\text { childcare }\end{array}\end{array}$}} \\
\hline & \multirow[t]{2}{*}{$\begin{array}{c}\text { Above-median } \\
\text { childcare } \\
\end{array}$} & \multicolumn{2}{|c|}{$\begin{array}{c}\text { Below-median } \\
\text { childcare }\end{array}$} & & & \multirow[t]{2}{*}{$\begin{array}{c}\begin{array}{c}\text { Above-median } \\
\text { childcare }\end{array} \\
\end{array}$} & \multicolumn{2}{|c|}{$\begin{array}{l}\text { Below-median } \\
\text { childcare }\end{array}$} & & \\
\hline & & unmatched & matched & unmatched & matched & & (unmatched) & (matched) & unmatched & matched \\
\hline \multicolumn{11}{|l|}{ Individual-Level Characteristics } \\
\hline Mother's age & 33.50 & 32.98 & 33.50 & 10.0 & 0.0 & 32.03 & 32.32 & 32.03 & -6.20 & 0.0 \\
\hline Medium education & 0.54 & 0.65 & 0.54 & -22.4 & 0.0 & 0.58 & 0.61 & 0.58 & -4.10 & 0.0 \\
\hline Migration background & 0.35 & 0.27 & 0.35 & 17.4 & 0.0 & 0.07 & 0.08 & 0.07 & 0.00 & 0.0 \\
\hline Partnered cohabiting & 0.09 & 0.14 & 0.09 & -12.5 & 0.0 & 0.32 & 0.25 & 0.32 & 13.30 & 0.0 \\
\hline Single & 0.05 & 0.06 & 0.05 & -9.1 & 0.0 & 0.14 & 0.13 & 0.14 & 0.00 & 0.0 \\
\hline Importance of job & 0.89 & 1.10 & 0.89 & -17.9 & 0.0 & 1.00 & 0.98 & 1.00 & 1.90 & 0.0 \\
\hline Importance of job (m) & 0.60 & 0.50 & 0.60 & 20.0 & 0.0 & 0.51 & 0.48 & 0.51 & 6.00 & 0.0 \\
\hline Income prenatal & 20.70 & 20.81 & 20.70 & -0.5 & 0.0 & 11.57 & 10.35 & 11.57 & 7.60 & 0.0 \\
\hline Income prenatal (m) & 0.40 & 0.36 & 0.40 & 6.1 & 0.0 & 0.32 & 0.33 & 0.32 & -2.10 & 0.0 \\
\hline Household-equivalent-income & 1391.00 & 1266.00 & 1390.00 & 17.4 & 0.1 & 984.00 & 1006.00 & 983.90 & -4.00 & 0.0 \\
\hline 2 children & 0.57 & 0.48 & 0.57 & 18.0 & 0.0 & 0.52 & 0.50 & 0.52 & 4.00 & 0.0 \\
\hline Part-time prenatal & 0.19 & 0.21 & 0.19 & -5.0 & 0.0 & 0.15 & 0.10 & 0.15 & 15.20 & 0.0 \\
\hline Full-time prenatal & 0.26 & 0.24 & 0.26 & 2.3 & 0.0 & 0.33 & 0.38 & 0.33 & -12.50 & 0.0 \\
\hline Employment prenatal (m) & 0.32 & 0.24 & 0.32 & 17.8 & 0.0 & 0.20 & 0.19 & 0.20 & 2.50 & 0.0 \\
\hline Employment experience & 0.34 & 0.35 & 0.34 & -5.9 & 0.0 & 0.34 & 0.33 & 0.34 & 5.00 & 0.0 \\
\hline Experience missing & 0.05 & 0.03 & 0.05 & 10.0 & 0.0 & 0.04 & 0.03 & 0.04 & 0.00 & 0.0 \\
\hline Parental leave prior 2007 & 0.12 & 0.30 & 0.12 & -45.0 & 0.0 & 0.22 & 0.20 & 0.22 & 2.40 & 0.0 \\
\hline \multicolumn{11}{|l|}{ County-level characteristics } \\
\hline Unemployment rate & 6.52 & 6.77 & 6.52 & -8.9 & 0.0 & 12.90 & 12.33 & 12.90 & 18.20 & 0.0 \\
\hline GDP per Capita & 40.67 & 29.63 & 40.67 & 72.2 & 0.0 & 23.09 & 25.93 & 23.09 & -48.60 & 0.0 \\
\hline Rural County & 0.24 & 0.35 & 0.24 & -26.7 & 0.0 & 0.73 & 0.37 & 0.73 & 74.50 & 0.0 \\
\hline $\mathrm{N}$ & 2276 & 2086 & & & 4362 & 628 & 693 & & & 1321 \\
\hline Mothers & 1054 & 909 & & & 1817 & 286 & 297 & & & 550 \\
\hline Counties & 184 & 121 & & & 282 & 58 & 34 & & & 72 \\
\hline
\end{tabular}

Note: Bold figures indicate significant mean differences between mothers with above and below-median childcare before matching (t-test).

Source: SOEP v33 (2007-2016). 
Table A3 Average marginal effects of above-median childcare availability on maternal employment (multinomial logistic regressions)

\begin{tabular}{|c|c|c|c|c|c|c|}
\hline & \multicolumn{3}{|c|}{ West Germany } & \multicolumn{3}{|c|}{ East Germany } \\
\hline & All births & $1^{\text {st }}$ birth & $2^{\text {nd }}$ birth & All births & $1^{\text {st }}$ birth & $2^{\text {nd }}$ birth \\
\hline & M1 & M2 & M3 & M1 & M2 & M3 \\
\hline Not working & $\begin{array}{l}-0.07 * * \\
(0.03)\end{array}$ & $\begin{array}{l}-0.08 * * \\
(0.03)\end{array}$ & $\begin{array}{l}-0.06 * \\
(0.03)\end{array}$ & $\begin{array}{l}-0.01 \\
(0.03)\end{array}$ & $\begin{array}{l}-0.00 \\
(0.04)\end{array}$ & $\begin{array}{l}-0.04 \\
(0.04)\end{array}$ \\
\hline Marginal & $\begin{array}{l}-0.02 \\
(0.02) \\
\end{array}$ & $\begin{array}{l}-0.01 \\
(0.02) \\
\end{array}$ & $\begin{array}{l}-0.02 \\
(0.02) \\
\end{array}$ & $\begin{array}{l}-0.00 \\
(0.01) \\
\end{array}$ & $\begin{array}{l}-0.01 \\
(0.01) \\
\end{array}$ & $\begin{array}{c}0.03+ \\
(0.02) \\
\end{array}$ \\
\hline Part-time & $\begin{array}{l}0.06^{* *} \\
(0.02) \\
\end{array}$ & $\begin{array}{l}0.08 * * \\
(0.03) \\
\end{array}$ & $\begin{array}{c}0.03 \\
(0.02) \\
\end{array}$ & $\begin{array}{c}0.01 \\
(0.03) \\
\end{array}$ & $\begin{array}{l}-0.01 \\
(0.04)\end{array}$ & $\begin{array}{c}0.01 \\
(0.04) \\
\end{array}$ \\
\hline Full-time & $\begin{array}{c}0.03 * \\
(0.01) \\
\end{array}$ & $\begin{array}{c}0.01 \\
(0.02) \\
\end{array}$ & $\begin{array}{l}0.05^{* *} \\
(0.01) \\
\end{array}$ & $\begin{array}{c}0.00 \\
(0.03) \\
\end{array}$ & $\begin{array}{c}0.02 \\
(0.04) \\
\end{array}$ & $\begin{array}{l}-0.01 \\
(0.04) \\
\end{array}$ \\
\hline $\mathrm{N}$ & 4362 & 1905 & 2457 & 1321 & 575 & 746 \\
\hline $\mathrm{N}$ treated & 2276 & 976 & 1300 & 628 & 301 & 327 \\
\hline Counties & 282 & 255 & 251 & 72 & 62 & 68 \\
\hline
\end{tabular}

Notes: Robust standard errors clustered on county level in parentheses. $+\mathrm{p}<0.1{ }^{*} \mathrm{p}<0.05$. ${ }^{* *} \mathrm{p}<0.01$

Source: SOEP v33 linked with county-level data (2007-2016). 
Table A4 Average marginal effects of above-median childcare availability on maternal employment by level of education (multinomial logistic regressions)

\begin{tabular}{|c|c|c|c|c|c|c|c|c|c|c|c|c|c|c|c|}
\hline & \multicolumn{9}{|c|}{ West Germany } & \multicolumn{6}{|c|}{ East Germany ${ }^{1}$} \\
\hline & \multicolumn{3}{|c|}{ High } & \multicolumn{3}{|c|}{ Medium } & \multicolumn{3}{|c|}{ Low $^{1}$} & \multicolumn{3}{|c|}{ High } & \multicolumn{3}{|c|}{ Medium } \\
\hline & All & $1^{\text {st }}$ birth & $2^{\text {nd }}$ birth & All & $1^{\text {st }}$ birth & $2^{\text {nd }}$ birth & All & $1^{\text {st }}$ birth & $2^{\text {nd }}$ birth & All & $1^{\text {st }}$ birth & $2^{\text {nd }}$ birth & All & $1^{\text {st }}$ birth & $2^{\text {nd }}$ birth \\
\hline & M1 & M2 & M3 & M4 & M5 & M6 & M7 & M8 & M9 & M1 & M2 & M3 & M4 & M5 & M6 \\
\hline Not working & $\begin{array}{l}-0.08+ \\
(0.04)\end{array}$ & $\begin{array}{l}-0.08 \\
(0.05)\end{array}$ & $\begin{array}{l}-0.03 \\
(0.04) \\
\end{array}$ & $\begin{array}{l}-0.03 \\
(0.02)\end{array}$ & $\begin{array}{l}-0.02 \\
(0.03)\end{array}$ & $\begin{array}{l}-0.03 \\
(0.03) \\
\end{array}$ & $\begin{array}{l}-0.11^{*} \\
(0.05)\end{array}$ & $\begin{array}{l}-0.04 \\
(0.08)\end{array}$ & $\begin{array}{l}-0.15+ \\
(0.08)\end{array}$ & $\begin{array}{c}0.03 \\
(0.05)\end{array}$ & $\begin{array}{l}-0.01 \\
(0.05)\end{array}$ & $\begin{array}{c}0.03 \\
(0.05)\end{array}$ & $\begin{array}{l}-0.00 \\
(0.04)\end{array}$ & $\begin{array}{l}0.08 * \\
(0.04)\end{array}$ & $\begin{array}{l}-0.04 \\
(0.04)\end{array}$ \\
\hline Marginal & $\begin{array}{c}0.03 \\
(0.02) \\
\end{array}$ & $\begin{array}{l}-0.01 \\
(0.03) \\
\end{array}$ & $\begin{array}{l}-0.01 \\
(0.03) \\
\end{array}$ & $\begin{array}{l}-0.05^{*} \\
(0.02) \\
\end{array}$ & $\begin{array}{l}-0.02 \\
(0.02) \\
\end{array}$ & $\begin{array}{l}-0.05^{*} \\
(0.02) \\
\end{array}$ & $\begin{array}{l}-0.03 \\
(0.04) \\
\end{array}$ & $\begin{array}{c}0.03 \\
(0.04) \\
\end{array}$ & $\begin{array}{l}-0.05 \\
(0.06) \\
\end{array}$ & $\begin{array}{c}0.01 \\
(0.01) \\
\end{array}$ & $\begin{array}{l}0.00^{* *} \\
(0.00)\end{array}$ & $\begin{array}{c}0.02 \\
(0.02) \\
\end{array}$ & $\begin{array}{l}-0.00 \\
(0.01) \\
\end{array}$ & $\begin{array}{r}-0.01+ \\
(0.01) \\
\end{array}$ & $\begin{array}{c}0.07 * \\
(0.03) \\
\end{array}$ \\
\hline Part-time & $\begin{array}{c}0.03 \\
(0.03) \\
\end{array}$ & $\begin{array}{c}0.07 \\
(0.04) \\
\end{array}$ & $\begin{array}{l}-0.01 \\
(0.03) \\
\end{array}$ & $\begin{array}{c}0.06^{* *} \\
(0.02)\end{array}$ & $\begin{array}{c}0.05+ \\
(0.03) \\
\end{array}$ & $\begin{array}{r}0.05^{*} \\
(0.03) \\
\end{array}$ & $\begin{array}{l}0.12 * * \\
(0.04)\end{array}$ & $\begin{array}{c}0.05 \\
(0.06) \\
\end{array}$ & $\begin{array}{c}0.20 * * \\
(0.08)\end{array}$ & $\begin{array}{l}-0.00 \\
(0.04) \\
\end{array}$ & $\begin{array}{l}0.10^{*} \\
(0.04) \\
\end{array}$ & $\begin{array}{l}-0.01 \\
(0.06) \\
\end{array}$ & $\begin{array}{l}-0.03 \\
(0.03) \\
\end{array}$ & $\begin{array}{l}-0.05 \\
(0.05) \\
\end{array}$ & $\begin{array}{l}-0.02 \\
(0.04) \\
\end{array}$ \\
\hline Full-time & $\begin{array}{c}0.02 \\
(0.03) \\
\end{array}$ & $\begin{array}{c}0.02 \\
(0.05) \\
\end{array}$ & $\begin{array}{c}0.05^{*} \\
(0.02) \\
\end{array}$ & $\begin{array}{c}0.02 \\
(0.01) \\
\end{array}$ & $\begin{array}{l}-0.01 \\
(0.02) \\
\end{array}$ & $\begin{array}{c}0.03 * \\
(0.01) \\
\end{array}$ & $\begin{array}{c}0.02 \\
(0.03) \\
\end{array}$ & $\begin{array}{l}-0.05 \\
(0.06) \\
\end{array}$ & -1 & $\begin{array}{l}-0.04 \\
(0.04) \\
\end{array}$ & $\begin{array}{l}-0.09 * \\
(0.04) \\
\end{array}$ & $\begin{array}{l}-0.04 \\
(0.07) \\
\end{array}$ & $\begin{array}{c}0.03 \\
(0.04) \\
\end{array}$ & $\begin{array}{l}-0.02 \\
(0.07) \\
\end{array}$ & $\begin{array}{l}-0.00 \\
(0.04) \\
\end{array}$ \\
\hline $\mathrm{N}$ & 1351 & 597 & 754 & 2637 & 1121 & 1516 & 374 & 187 & 187 & 504 & 214 & 290 & 740 & 325 & 415 \\
\hline $\mathrm{N}$ treated & 878 & 397 & 481 & 1222 & 495 & 727 & 176 & 84 & 92 & 219 & 103 & 116 & 366 & 172 & 194 \\
\hline Counties & 180 & 137 & 146 & 253 & 215 & 219 & 119 & 83 & 72 & 50 & 42 & 44 & 70 & 55 & 62 \\
\hline
\end{tabular}

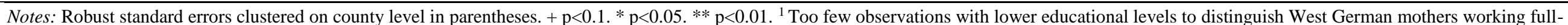

time after second births and between first and second births among East German mothers.

Source: SOEP v33 linked with county-level data (2007-2016). 
Table A5 Average marginal effects of above-median childcare availability on maternal employment by level of education (multinomial logistic regressions withoug entropy balancing)

\begin{tabular}{|c|c|c|c|c|c|c|c|c|c|c|c|c|c|c|c|}
\hline & \multicolumn{9}{|c|}{ West Germany } & \multicolumn{6}{|c|}{ East Germany ${ }^{1}$} \\
\hline & \multicolumn{3}{|c|}{ High } & \multicolumn{3}{|c|}{ Medium } & \multicolumn{3}{|c|}{ Low $^{1}$} & \multicolumn{3}{|c|}{ High } & \multicolumn{3}{|c|}{ Medium } \\
\hline & All & $1^{\text {st }}$ birth & $2^{\text {nd }}$ birth & All & $1^{\text {st }}$ birth & $2^{\text {nd }}$ birth & All & $1^{\text {st }}$ birth & $2^{\text {nd }}$ birth & All & $1^{\text {st }}$ birth & $2^{\text {nd }}$ birth & All & $1^{\text {st }}$ birth & $2^{\text {nd }}$ birth \\
\hline & M1 & M2 & M3 & M4 & M5 & M6 & M7 & M8 & M9 & M1 & $\mathrm{M} 2$ & M3 & M4 & M5 & M6 \\
\hline Not working & $\begin{array}{l}-0.00 \\
(0.03) \\
\end{array}$ & $\begin{array}{l}-0.04 \\
(0.04) \\
\end{array}$ & $\begin{array}{c}0.02 \\
(0.04) \\
\end{array}$ & $\begin{array}{l}-0.01 \\
(0.02) \\
\end{array}$ & $\begin{array}{l}-0.01 \\
(0.03) \\
\end{array}$ & $\begin{array}{l}-0.01 \\
(0.03) \\
\end{array}$ & $\begin{array}{l}-0.11^{*} \\
(0.06) \\
\end{array}$ & $\begin{array}{l}-0.05 \\
(0.09) \\
\end{array}$ & $\begin{array}{l}-0.18^{*} \\
(0.07) \\
\end{array}$ & $\begin{array}{c}0.03 \\
(0.05) \\
\end{array}$ & $\begin{array}{c}0.00 \\
(0.04) \\
\end{array}$ & $\begin{array}{c}0.03 \\
(0.05) \\
\end{array}$ & $\begin{array}{c}0.00 \\
(0.03) \\
\end{array}$ & $\begin{array}{c}0.09 \\
(0.07) \\
\end{array}$ & $\begin{array}{l}-0.02 \\
(0.04) \\
\end{array}$ \\
\hline Marginal & $\begin{array}{l}-0.03 \\
(0.02) \\
\end{array}$ & $\begin{array}{l}-0.02 \\
(0.03) \\
\end{array}$ & $\begin{array}{l}-0.03 \\
(0.03) \\
\end{array}$ & $\begin{array}{l}-0.05 * * \\
(0.02)\end{array}$ & $\begin{array}{l}-0.03 \\
(0.02) \\
\end{array}$ & $\begin{array}{l}-0.06^{* *} \\
(0.02)\end{array}$ & $\begin{array}{l}-0.01 \\
(0.04) \\
\end{array}$ & $\begin{array}{l}-0.01 \\
(0.04) \\
\end{array}$ & $\begin{array}{c}0.01 \\
(0.06) \\
\end{array}$ & $\begin{array}{c}0.01 \\
(0.01) \\
\end{array}$ & $\begin{array}{l}-0.00 \\
(0.00) \\
\end{array}$ & $\begin{array}{c}0.02 \\
(0.02) \\
\end{array}$ & $\begin{array}{l}-0.01 \\
(0.01) \\
\end{array}$ & $\begin{array}{l}-0.14 \\
(0.09) \\
\end{array}$ & $\begin{array}{c}0.02 \\
(0.02) \\
\end{array}$ \\
\hline Part-time & $\begin{array}{l}-0.01 \\
(0.03) \\
\end{array}$ & $\begin{array}{c}0.04 \\
(0.05) \\
\end{array}$ & $\begin{array}{l}-0.05 \\
(0.04) \\
\end{array}$ & $\begin{array}{c}0.06 * * \\
(0.02) \\
\end{array}$ & $\begin{array}{c}0.06^{*} \\
(0.03) \\
\end{array}$ & $\begin{array}{c}0.05^{*} \\
(0.02) \\
\end{array}$ & $\begin{array}{c}0.08 * * \\
(0.03) \\
\end{array}$ & $\begin{array}{c}0.02 \\
(0.05) \\
\end{array}$ & $\begin{array}{c}0.17 * * \\
(0.06) \\
\end{array}$ & $\begin{array}{l}-0.00 \\
(0.05) \\
\end{array}$ & $\begin{array}{c}0.03 \\
(0.06) \\
\end{array}$ & $\begin{array}{c}0.01 \\
(0.05) \\
\end{array}$ & $\begin{array}{l}-0.07 * \\
(0.03) \\
\end{array}$ & $\begin{array}{l}-0.01 \\
(0.06) \\
\end{array}$ & $\begin{array}{l}-0.07+ \\
(0.04) \\
\end{array}$ \\
\hline Full-time & $\begin{array}{c}0.04 \\
(0.03) \\
\end{array}$ & $\begin{array}{c}0.02 \\
(0.04) \\
\end{array}$ & $\begin{array}{c}0.05+ \\
(0.03) \\
\end{array}$ & $\begin{array}{c}0.01 \\
(0.01) \\
\end{array}$ & $\begin{array}{l}-0.02 \\
(0.02) \\
\end{array}$ & $\begin{array}{c}0.02 \\
(0.01) \\
\end{array}$ & $\begin{array}{c}0.04 \\
(0.04) \\
\end{array}$ & $\begin{array}{c}0.04 \\
(0.09) \\
\end{array}$ & -1 & $\begin{array}{l}-0.04 \\
(0.04) \\
\end{array}$ & $\begin{array}{l}-0.03 \\
(0.05) \\
\end{array}$ & $\begin{array}{l}-0.06 \\
(0.06) \\
\end{array}$ & $\begin{array}{c}0.07+ \\
(0.04) \\
\end{array}$ & $\begin{array}{c}0.07 \\
(0.06) \\
\end{array}$ & $\begin{array}{c}0.07 \\
(0.04) \\
\end{array}$ \\
\hline $\mathrm{N}$ & 1351 & 597 & 754 & 2637 & 1121 & 1516 & 374 & 187 & 187 & 504 & 214 & 290 & 740 & 325 & 415 \\
\hline Counties & 180 & 137 & 146 & 253 & 215 & 219 & 119 & 83 & 72 & 50 & 42 & 44 & 70 & 55 & 62 \\
\hline
\end{tabular}

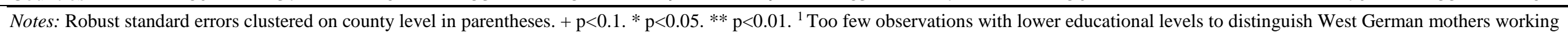
full-time after second births and between first and second births among East German mothers.

Source: SOEP v33 linked with county-level data (2007-2016). 
Table A6 Average marginal effects of above-median full-time childcare availability on maternal employment (logistic regressions)

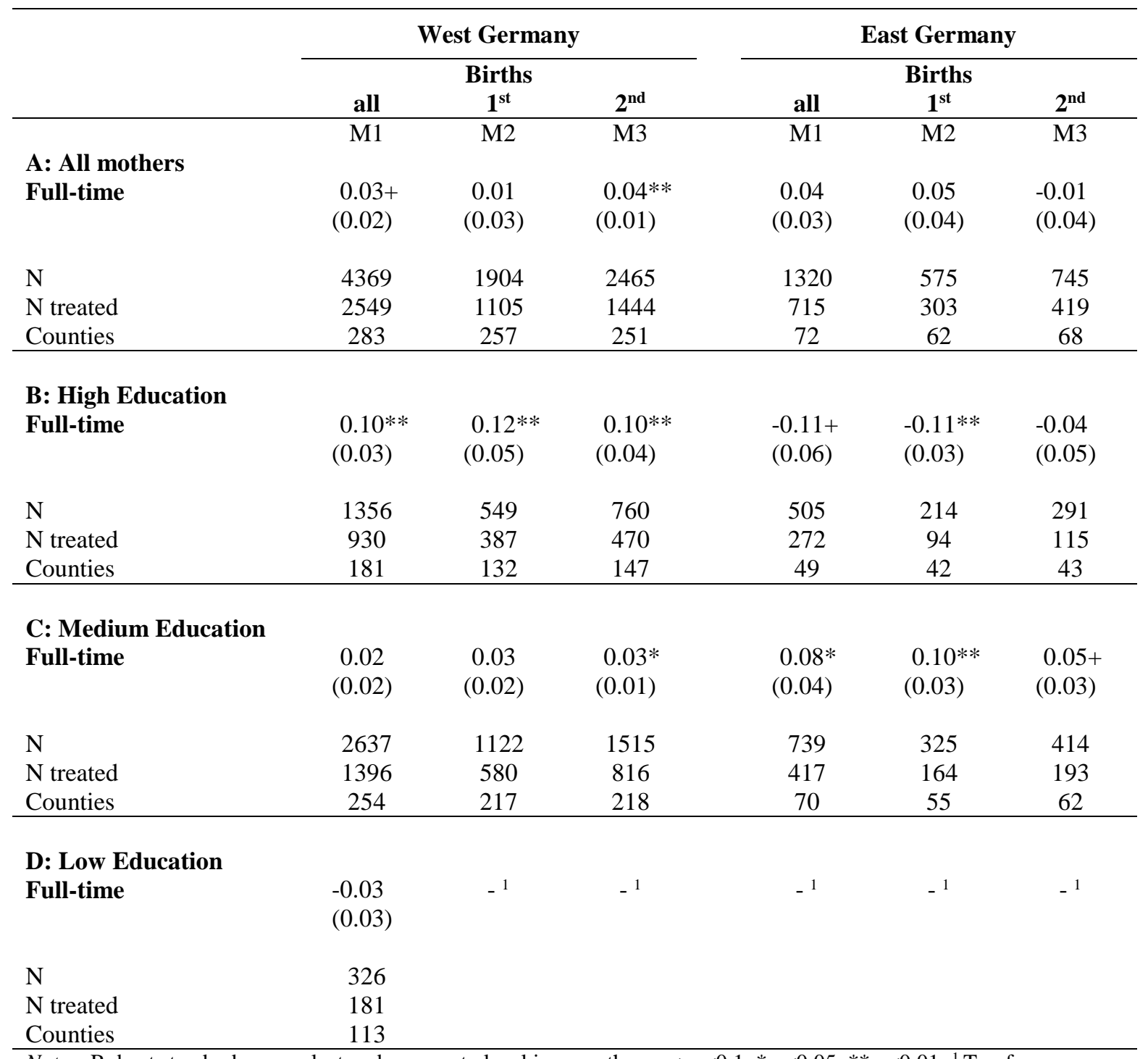

Notes: Robust standard errors clustered on county level in parentheses. $+\mathrm{p}<0.1 .{ }^{*} \mathrm{p}<0.05 . * * \mathrm{p}<0.01 .{ }^{1}$ Too few observations with lower educational levels.

Source: SOEP v33 linked with county-level data (2007-2016). 